\title{
ArcheoSciences
}

Revue d'archéométrie

33 (suppl.) | 2009

Mémoire du sol, espace des hommes

\section{D Inversion of Automated Resistivity Profiling (ARP) Data}

Nikos G. Papadopoulos, Gregory N. Tsokas, Michel Dabas, Myeong-Jong Yi and Panagiotis Tsourlos

\section{OpenEdition \\ 12 Journals}

\author{
Electronic version \\ URL: https://journals.openedition.org/archeosciences/1790 \\ DOI: $10.4000 /$ archeosciences. 1790 \\ ISBN: 978-2-7535-1599-4 \\ ISSN: $2104-3728$ \\ Publisher \\ Presses universitaires de Rennes \\ Printed version \\ Date of publication: 30 October 2009 \\ Number of pages: $329-332$ \\ ISBN: 978-2-7535-0943-6 \\ ISSN: 1960-1360 \\ Electronic reference \\ Nikos G. Papadopoulos, Gregory N. Tsokas, Michel Dabas, Myeong-Jong Yi and Panagiotis Tsourlos, \\ "3D Inversion of Automated Resistivity Profiling (ARP) Data", ArcheoSciences [Online], 33 (suppl.) | \\ 2009, Online since 30 October 2011, connection on 01 February 2022. URL: http:// \\ journals.openedition.org/archeosciences/1790 ; DOI: https://doi.org/10.4000/archeosciences. 1790
}




\title{
3D Inversion of Automated Resistivity Profiling (ARP) Data
}

\author{
Nikos G. Papadopoulos *, Gregory N. Tsokas **, Michel Dabas ***, \\ Myeong-Jong YI * and Panagiotis Tsourlos **
}

Key words: electrical resistivity, mobile quadripole, Automated Resistivity Profiling, 3D inversion, Andilly archaeological site.

Electrical resistivity is a well established and widely used prospection method. The technique has also become a valuable and inseparable tool in archaeological site evaluation and excavation planning (Clark, 1990). Nowadays, it is routinely used in mapping the sub-surface resistivity variation of an archaeological site. The compilation of maps that transform the geophysical results into images that resemble a plane view of buried relics comprises the ultimate goal of geoelectrical prospection in archaeological areas (Scollar $e t$ al., 1986).

The standard mapping technique is sufficient and successful in most routine field applications (Tsokas et al., 1994). On the other hand, the use of a fixed-array length throughout the field survey hinders the interpretation of collected resistivity data in areas with more complex surface geology, as the current cannot penetrate to deeper levels in order to gain more depth information. The development of multiplexing resistance systems provided a step-forward in the determination of three dimensional distribution of apparent resistivity (Walker, 2000).

Additionally, the need for conducting high-resolution surveys characterized by a small measurement mesh and reducing as mush as possible the survey cost without limiting the extent of the investigated area, has led to the development of mobile quadripoles allowing continuous measurement while moving (Panissod et al., 1997, 1998). These multi-electrode devices allow measurements over several depths of investigation in order to perform an exhaustive 3D exploration.

The Automatic Resistivity Profiling (ARP) method is a V-shaped multipole system with one transmitting dipole and three receiving dipoles, the length of which increases with their distance from the transmitter (Fig. 1a). This method reduces the effect of the superficial geophysical noise on larger receiver dipoles, it uses three investigation depths without switching and the size of the arrays remains limited to a value equivalent to that of the investigation depth (Panissod et al., 1997; Dabas, 2009). The collected apparent resistivity data are presented in the form of 3 maps corresponding to the different measuring dipoles and the recorded anomalies are interpreted in terms of possible buried archaeological structures. These maps represent the cumulative volume contribution of the soil from top to the three increasing depth of investigations.

In special cases where a more quantitative interpretation is necessary, the $3 \mathrm{D}$ resistivity inversion of the data can provide additional information about the burial depth and the depth extent of buried relics (Papadopoulos et al., 2007). The resistivity inversion scheme starts by lineariz-

\footnotetext{
* Korea Institute of Geosciences and Mineral Resources (KIGAM), Mineral Resources Research Division, Laboratory of Resource Exploration Development, 92 Gwahang-no, Yuseong-gu, Daejeon, 305-350, S. Korea. (nikos@ims.forth.gr)

** Department of Geophysics, School of Geology, Aristotle University of Thessaloniki, 54124, Thessaloniki, Greece.

*** Geocarta, 16 rue du Sentier, 75002 Paris, France.
} 

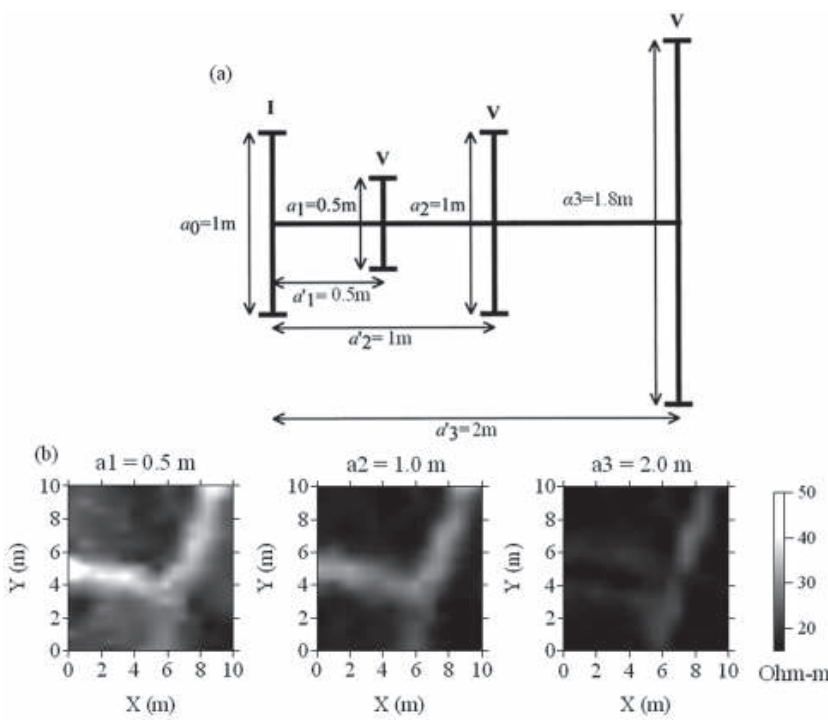

Figure 1: a) Diagram of the ARP configuration. b) Extracted apparent resistivity data from Andilly archaeological site which were inverted with the $3 \mathrm{D}$ inversion algorithm.

ing the inverse problem and minimizing the data misfit in the least squares sense. The instability and non-uniqueness of the inverse problem is approached by imposing specific smoothness constraints (Sasaki, 1994). In this work, a relatively small region from a wider area previously explored by the ARP method was selected and re-processed by a 3D resistivity inversion algorithm in order to acquire a more quantitative model of the buried archaeological structure.

A large geophysical exploration was undertaken at Andilly archaeological site in France. An area of more than 17,500 square meters was investigated with the ARP method. The transmitting and receiving electrode configuration for the mobile device is shown in figure 1(a). The data were acquired along $1 \mathrm{~m}$ parallel spaced profiles at $0.2 \mathrm{~m}$ sampling rate. A Kriging interpolation algorithm was used to grid the data at $0.5 \mathrm{~m}$ spacing in both horizontal directions. Two large rectangular high apparent-resistivity anomalies are outlined at the center and at the east of the surveyed area. Some rectangular structures are also visible at the southeastern corner of the region. These anomalies are registered in all the maps that correspond to the different length of the receiving dipoles.

A $10 \times 10 \mathrm{~m}$ area, which encloses the connection of two vertical structures (Fig. 1b), was extracted from the re-sampled original data. These data were used as input into the $3 \mathrm{D}$ resistivity inversion algorithm. The geometry and the coordinates of the electrodes were appropriately configured by assigning to every different measurement a unique four- electrode combination (Fig. 2a), based on the electrode configuration of figure 1(a) and the step interval of $0.5 \mathrm{~m}$ along the $\mathrm{X}$ and $\mathrm{Y}$ axes. This data transformation resulted in 1873 different electrode positions which cover the $10 \times 10 \mathrm{~m}$ grid and 1323 measurements that described the $3 \mathrm{D}$ apparent resistivity variation.

The subsurface resistivity distribution was described by $3750(25 \times 26 \times 5)$ cubic parameters. The horizontal dimensions and the thickness of these parameters were set equal to the $0.5 \mathrm{~m}$ re-sampled step interval of the ARP survey. The thick lines in figure $2(\mathrm{~b}, \mathrm{c})$ indicate the parameters of constant resistivity into which the area was divided. On the other hand, the thin lines show the distribution of $3 \mathrm{D}$ elements that form a specific parameter. These elements formulate the 3D Finite Element Mesh (FEM) which was used to calculate the synthetic apparent resistivity data in the inversion procedure. A 3D Finite Element inversion algorithm was used to process and invert the ARP data. The inversion procedure is based on a smoothness constrained Gauss-

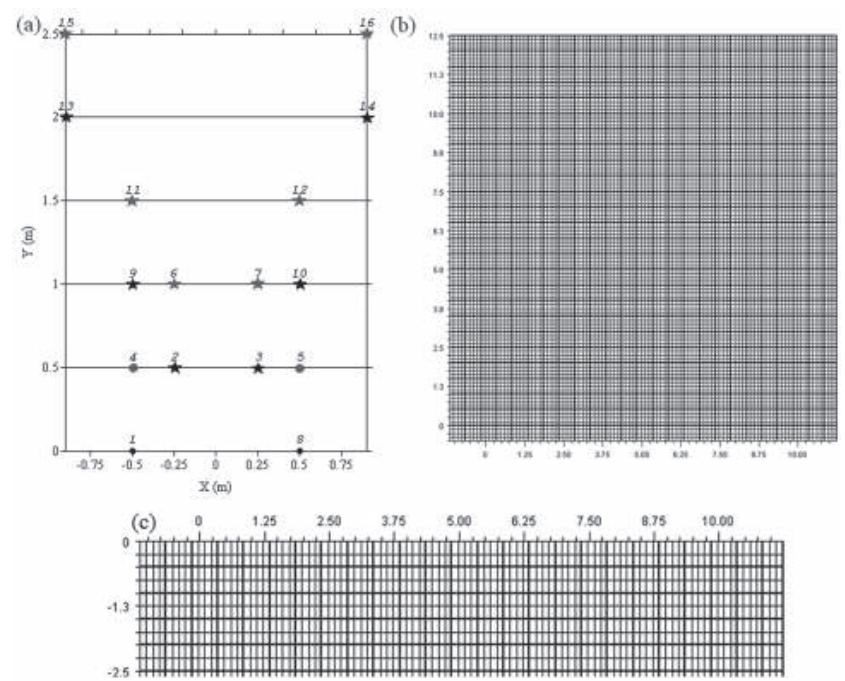

Figure 2: a) Electrode geometry corresponding to two successive positions of the ARP system along the Y-axis. The circles and the stars indicate the position of the transmitting and the receiving electrodes respectively. For the first ARP position (black colour) the current is transmitted into the earth through electrodes 1 and 8 and the potential difference is measured at electrodes 2-3, 9-10 and 13-14 which correspond to the different length of the receiving dipoles. The second ARP position (red colour) involves the use of electrodes 4 and 5 as transmitting electrodes and the electrode pairs 6-7, 11-12 and 15-16 as receiving dipoles. b) X-Y plane of the $3 \mathrm{D}$ parameter and FEM mesh used for the inversion of the data. c) X-Z plane of the 3D parameter and FEM mesh. The thick lines indicate parameters of constant resistivity. Each parameter was divided into $4 \times 4 \times 2$ elements (light lines). 


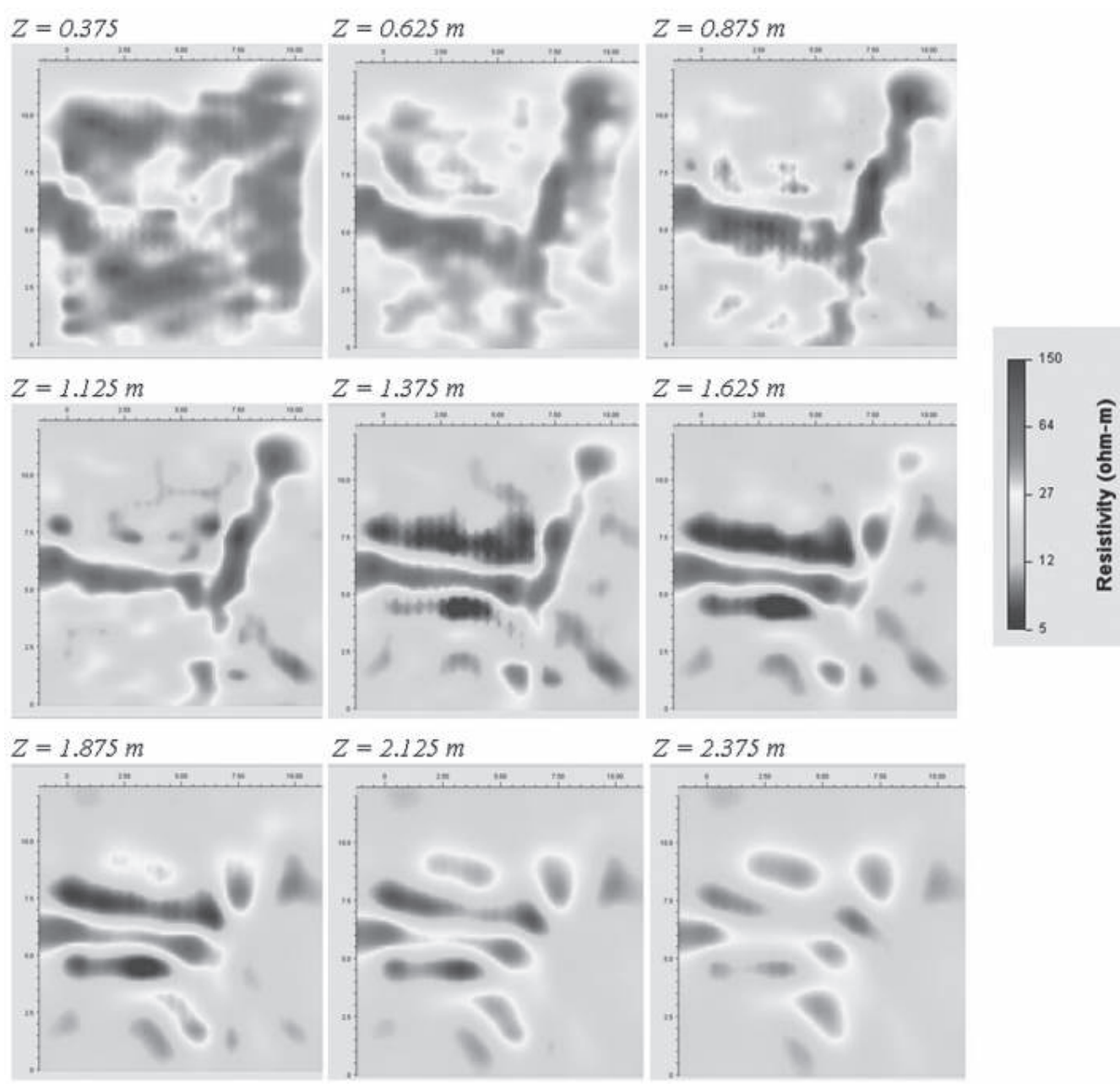

Figure 3 (see color plate): 3D resistivity inversion model of the $10 \times 10 \mathrm{~m}$ area in the Andilly archaeological site.
Newton algorithm. The Active Constraint Balancing (ACB) method was also incorporated in the inversion in order to enhance the least-squares resolving power and stability (Yi et al., 2001). The values of 0.01 and 1 were used for the lower $\left(\lambda_{\min }\right)$ and the upper $\left(\lambda_{\max }\right)$ bounds of the Lagrange multiplier respectively. These values are necessary for the spread function analysis and they were defined $a$ priori by conducting some initial test inversions in the data set.

The inversion algorithm converged to a final 3D resistivity model after 7 iterations and $R M S=2.3 \%$. Horizontal depth slices every $0.25 \mathrm{~m}$ were extracted from the inversion model and they are presented in figure 3 . The superficial layer $(Z=0.375 \mathrm{~m})$ has large resistivity variations. The two vertical structures appear from the depth $Z=0.625 \mathrm{~m}$ and reach the depth of $Z=1.625 \mathrm{~m}$ below ground surface. The maximum burial depth of the structures does not exceed $2.3 \mathrm{~m}$. Some faint remnants below that depth are due to the limited resolution of the surface electrical survey and the smoothness constraints imposed in order to stabilize the inversion procedure.
The 3D inversion managed to reconstruct the subsurface resistivity and identify the two vertical structures. Additional information concerning the burial depth and the depth extent of the archaeological features was extracted by the inversion. Compared to the three ARP apparent resistivity maps, $3 \mathrm{D}$ inversion can provide a more quantitative insight of the data. This information is very important to the archaeological team in order to plan more accurately future excavation projects.

On the other hand, the application of the ARP method involves the collection of a huge amount of data. This actually prohibits the $3 \mathrm{D}$ inversion of such data sets. So the inversion can only be applied in relatively small areas that exhibit a special interest and for which extra information concerning more quantitative characteristics needs to be determined. 


\section{Acknowledgements}

The research was supported by the Basic Research Project of the Korea Institute of Geoscience and Mineral Resources funded by the Ministry of Knowledge Economy of Korea.

\section{References}

Clark, A., 1990. Seeing Beneath the Soil. Prospecting Methods in Archaeology. B.T. Batsford Ltd, London.

Dabas, M., 2009. Theory and practice of the new fast electrical imaging system ARP. In Campana, S., Piro, S., (dir.). Seeing the Unseen, Taylor and Francis Group, London, 105-126.

Panissod, C., Dabas, A., Jolinet, A., Tabbagh, A., 1997. A novel mobile multipole system (MUCEP) for shallow (0-3 m) geoelectrical investigation: the "Vol-de-canards" array. Geophysical Prospecting, 45: 983-1002.

Panissod, C., Dabas, M., Hesse, A., Jolivet, A., Tabbagh, J., TaвbaGh, A., 1998. Recent developments in shallow-depth electrical and electrostatic prospecting using mobile arrays. Geophysics, 63, 5: 1542-1550.
Papadopoulos, N.G., Tsourlos, P., Tsokas, G.N., Sarris, A., 2007. Efficient ERT measuring and inversion strategies for 3D imaging of buried antiquities. Near Surface Geophysics, 5: 349-362.

SASAKI, Y., 1994. 3D Inversion using the Finite Element Method. Geophysics, 59: 1839-1848.

Scollar, I., Weinder, B., Segeth, K., 1986. Display of archaeological magnetic data. Geophysics, 51: 623-633.

Tsokas, G.N., Giannopoulos, A., Tsourlos, P., Vargemezis, G., Tealby, J.M., Sarris, A., Papazachos, C.B., Savopoulou, T., 1994. A large scale geophysical survey in the archaeological site of Europos (northern Greece). Journal of Applied Geophysics, 32: 85-98.

WALKER, A.R., 2000. Multiplexed resistivity survey at the roman town of Wroxeter. Archaeological Prospection, 7: 119-132.

YI, M.-J., Кim, J.-H., Song, Y., Сно, S.-J., Chung, S.-H., Suh, J.-H., 2001. Three-dimensional imaging of subsurface structures using resistivity data. Geophysical Prospecting, 49: 483497. 